\title{
Light Olefin Diffusion during the MTO Process on H-SAPO-34: A Complex Interplay of Molecular Factors
}

Pieter Cnudde, ${ }^{\S}$ Ruben Demuynck, ${ }^{\S}$ Steven Vandenbrande, Michel Waroquier, German Sastre, and Veronique Van Speybroeck*

Cite This: J. Am. Chem. Soc. 2020, 142, 6007-6017

Read Online

\section{ACCESS |}

山lll Metrics \& More

Article Recommendations

Supporting Information

ABSTRACT: The methanol-to-olefins process over H-SAPO-34 is characterized by its high shape selectivity toward light olefins. The catalyst is a supramolecular system consisting of nanometer-sized inorganic cages, decorated by Brønsted acid sites, in which organic compounds, mostly methylated benzene species, are trapped. These hydrocarbon pool species are essential to catalyze the methanol conversion but may also clog the pores. As such, diffusion of ethene and propene plays an essential role in determining the ultimate product selectivity. Enhanced sampling molecular dynamics simulations based on either force fields or density functional theory are used to determine how molecular factors influence the diffusion of light olefins through the 8-ring windows of H-SAPO-34. Our simulations show that diffusion through the 8-ring in general is a hindered process, corresponding to a hopping event of the diffusing molecule between neighboring cages. The loading of different methanol, alkene, and aromatic species in the cages

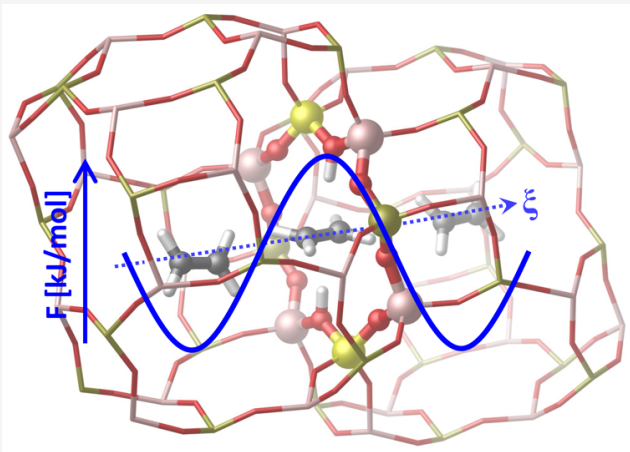
may substantially slow down or facilitate the diffusion process. The presence of Brønsted acid sites in the 8-ring enhances the diffusion process due to the formation of a favorable $\pi$-complex host-guest interaction. Aromatic hydrocarbon pool species severely hinder the diffusion and their spatial distribution in the zeolite crystal may have a significant effect on the product selectivity. Herein, we unveil how molecular factors influence the diffusion of light olefins in a complex environment with confined hydrocarbon pool species, high olefin loadings, and the presence of acid sites by means of enhanced molecular dynamics simulations under operating conditions.

\section{INTRODUCTION}

The production of bulk chemicals such as ethene and propene from alternative feedstocks (carbon dioxide, biomass, waste, natural gas, ...) is a very topical subject given the depleting fossil fuel reserves and the search for more sustainable technologies. Within this context the methanol-to-olefins (MTO) process can play a key role. Although the process was already introduced in the late 1970s, the catalytic technology has only recently been implemented on a large industrial scale. ${ }^{1-5}$ The MTO process typically occurs on an acid zeotype catalyst whose shape-selective micropores play a crucial role in the ultimate product selectivity. ${ }^{4,6-10}$ The discovery of H-SAPO-34 by the researchers of Union Carbide was a landmark in the exploration of this shape selectivity toward light olefins. H-SAPO-34 is a small-pore material, featuring the CHA topology, in which spacious cages are connected by small 8-ring windows (Figure 1). The material is also the core catalyst in the MTO technology developed by the Dalian Institute of Chemical Physics (DICP). ${ }^{5,11}$ Unfortunately, H-SAPO-34 also quickly deactivates and various strategies have been explored to improve the lifetime. ${ }^{12,13}$

A consensus was reached that in these small-pore zeolites a pool of (aromatic) hydrocarbons (HP) is formed, as originally proposed by Dahl and Kolboe. ${ }^{14,15}$ These HP species remain trapped in the zeolite cavities and act as cocatalysts. In a closed catalytic cycle, they undergo repeated methylation reactions with methanol and subsequent light olefin elimination, thus regenerating the HP species (Figure 1a). However, HP species can also transform via secondary reactions with primary olefinic products or methanol into polyaromatics (coke), which deactivate the catalytic ability of the zeolite by pore blocking or poisoning of the active sites. ${ }^{16-19}$ Finding the ideal acid site density is crucial to achieve an optimal efficiency of the catalyst (light olefin production versus coke formation). ${ }^{20}$ Within H-SAPO-34, the active HP species are believed to be hexamethylbenzenes which cannot migrate through the 8-ring windows connecting the different cages. According to Haw's initial proposal, a typical MTO catalyst becomes as such a supramolecular system with a nanometer-size inorganic cage

Received: September 23, 2019

Published: March 11, 2020 
(a)

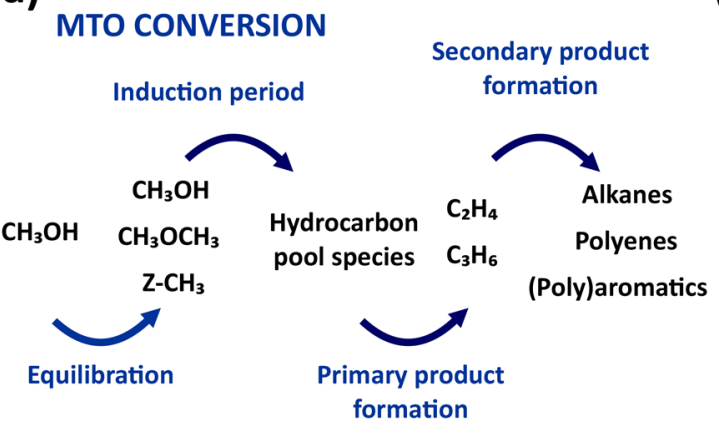

(b)

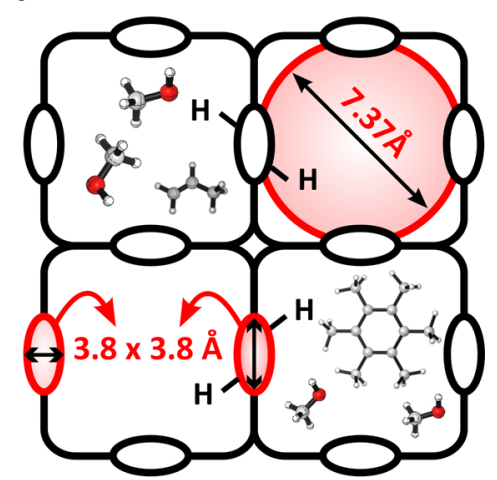

(c)

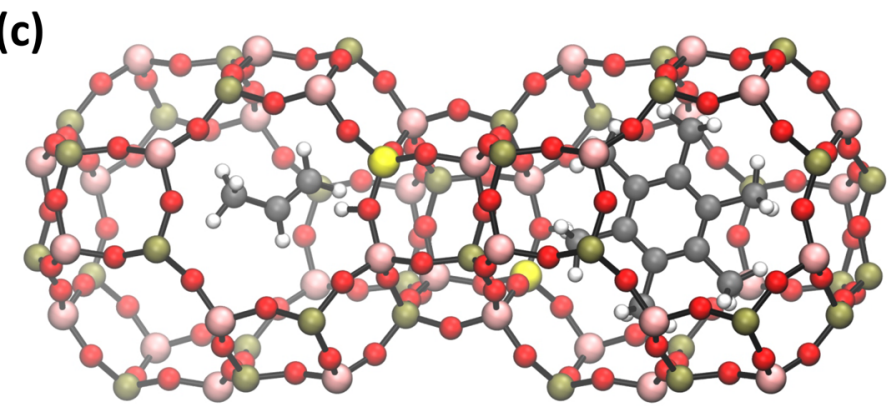

Figure 1. (a) Reaction scheme of the MTO process. (b) Scheme of the H-SAPO-34 pore system with large cages connected via 8-ring windows. (c) Representation of an H-SAPO-34 cell with two adjacent cages containing HP species. Color code: Al (pink), P (ocher), Si (yellow), O (red), H (white), C (gray).

decorated by Brønsted acid sites (BASs) and an essential organic compound. ${ }^{21}$ This catalytic system produces light olefins, mostly ethene and propene, with high selectivity. Once formed, these olefins need to diffuse through the crystal. In the MTO process, the loading of the zeolite pores dynamically evolves with time on stream. ${ }^{22-25}$ The presence of Brønsted acid sites in H-SAPO-34 has been shown to be an important factor in the diffusion process, ${ }^{26,27}$ although the precise role of the distribution of BASs has not yet been unraveled.

Since the MTO chemistry is governed by a complex reaction network with both temporal and spatial gradients, various factors may contribute to the observed product distribution and selectivities. ${ }^{28-31}$ Bhan and co-workers recently developed a method for analyzing transport phenomena in complex processes and discovered that diffusional constraints had the largest effect on some particular steps of the MTO reaction cycle. ${ }^{31}$ Hereijgers et al. performed seminal work to understand the selectivity and deactivation on H-SAPO-34. ${ }^{9}$ They showed that the product distribution is controlled by product shape selectivity. Initially, methanol would freely diffuse through the crystals and adsorb on the acid sites. After the formation of the first methylbenzenes in the outer cages of the crystals, the catalytic MTO cycle produces alkenes which diffuse out of the crystals. However, the selectivity toward ethene increased with time on stream, which was attributed to an increased diffusion hindrance of propene and the higher alkenes. ${ }^{32,33}$ At the same time, a tendency toward less methylated benzenes in the occluded aromatics was observed, although most of these methylbenzenes were not accessible for methanol in the nearly deactivated catalysts, as was shown by labeling experiments. This result was also confirmed by Weckhuysen et al., who showed by in situ spectroscopy that with time on stream fluorescent molecules were formed inside the crystals, but not on the outer surface of the crystals. ${ }^{34}$ These results indicated that only a minor fraction of the catalyst is active at any point in time and that the increased ethene selectivity could be attributed to diffusional limitations of longer alkenes due to pore blocking. The importance of diffusion for the production of alkenes and the difference between $\mathrm{H}$-SAPO-34 and $\mathrm{H}$ ZSM-5 was already pointed out in a relatively old study by Iglesia et al., who demonstrated the diffusional constraints imposed by the small connections between intracrystalline cavities and the importance of acid site densities for maximization of ethene selectivities. ${ }^{35}$

Recently, several experimental studies reported the strong correlation between the product distribution of the MTO process and the diffusivity of small hydrocarbon products. ${ }^{36-40}$ In parallel some interesting studies appeared which showed that also other factors contribute to the selectivity, such as the prevalence of some reaction cycles and intermediates. ${ }^{41}$ In comparison to the extensive set of experimental studies on diffusivity in H-SAPO-34, a molecular understanding of the diffusion of alkenes through H-SAPO-34 is still relatively limited. Some computational studies, using atomic force fields and molecular dynamics simulations, explored the role of temperature and different zeolite pore topologies (pure silica CHA and pure silica SAS) on the diffusivity of propane and propene. ${ }^{42}$ In ref 43 , Vidoni et al. determined experimentally the diffusion coefficients of ethane and ethene in pure silica DDR and made a comparison with the behavior of methane. Ghysels et al. performed regular force field based molecular dynamics simulations for the diffusion of ethene through various 8-ring zeolites. ${ }^{44}$ It was observed that the guest molecule spends most of the time in the cages and occasionally diffuses from one cage to another. The diffusion of propene has so far not been studied with first-principles methods. The simulation of propene diffusion through the 8-ring windows is 
(a)

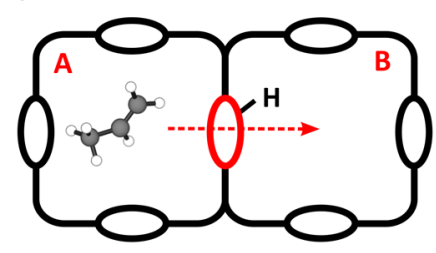

(b)

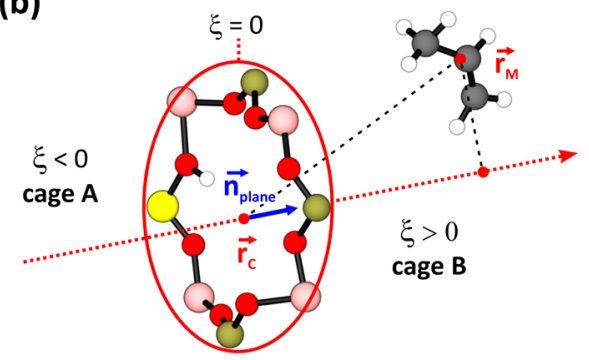

(c)

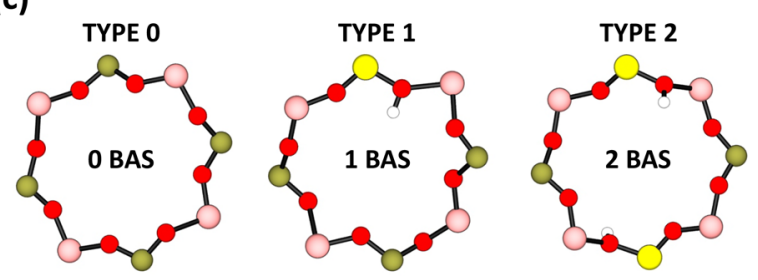

Figure 2. (a) Representation of propene diffusion through an 8-ring of H-SAPO-34 connecting adjacent cages A and B. (b) Scheme of collective variables for light olefin diffusion through an 8-ring of H-SAPO-34. (c) Different 8-ring types of H-SAPO-34 containing 0 BASs, 1 BAS, or 2 BASs.

not straightforward, as a barrier needs to be overcome to hop between cages.

In this work, diffusion is studied in a complex dynamic molecular environment representative of the actual MTO process. For the first time, we combine a first-principles description and enhanced sampling techniques to study the diffusion of light olefins in H-SAPO-34 on a molecular scale. The constructed models try to reflect the real MTO catalyst, taking into account the presence of Brønsted acid sites, hydrocarbon pool species, and high methanol loadings. For these model systems, free energy profiles for ethene and propene diffusion through the pores of the zeolite are determined using molecular dynamics simulations within an ab initio approach to properly account for all molecular interactions. Since unfeasibly long time scales would be required to sample the transition state region with sufficient accuracy, ${ }^{45,46}$ enhanced sampling methods are inevitable to properly simulate the activated diffusion process. ${ }^{47}$ Herein, we first discuss the influence of temperature on the diffusion rate, which allows us to disentangle effects related to entropy and enthalpy. Second, the effect of different propene loadings is considered to assess how the presence of other hydrocarbon species in the cages affects the diffusivity. Third, the effect of the presence of BASs in the 8-ring window is explored. Finally, the influence of a typical MTO environment with hydrocarbon pool species and methanol molecules on the diffusion mechanism of propene is investigated. The followed approach is unique of its kind and yields molecular level insight into the different elements affecting the light olefin diffusion in $\mathrm{H}$ SAPO-34 under operating conditions. In a sense, this study aims at following in operando the diffusivity of olefins during the MTO process.

\section{COMPUTATIONAL METHODS AND MODELS}

2.1. SAPO-34 Framework. SAPO-34 exhibits the CHA topology in which large cages $(11 \AA \times 6.7 \AA)$ are interconnected by small 8ring windows $(3.8 \AA \times 3.8 \AA)$. Each cage contains 6 8-rings as displayed in Figure 2. The SAPO-34 unit cell with composition $\left(\mathrm{AlPO}_{4}\right)_{18}$ contains $36 \mathrm{~T}$-sites. Brønsted acid sites were created by substitution of a $\mathrm{P}$ atom by a $\mathrm{Si}$ atom and addition of a chargecompensating proton. Substitution of an $\mathrm{Al}$ atom can also take place, but this configuration was not retained in this work. Experimental studies indicated an optimal $(\mathrm{Al}+\mathrm{P}) / \mathrm{Si}$ ratio of approximately 11 for the MTO process: i.e., with minimal catalyst deactivation. ${ }^{9,48}$ This ratio corresponds to the presence of $3 \mathrm{Si}$ atoms per unit cell, or approximately 2 Brønsted acid sites per cage, although no strict conditions were imposed regarding their position and their distribution throughout the material.

The SAPO-34 unit cell dimensions were obtained from a 20 ps preliminary ab initio molecular dynamics simulation in the $\mathrm{NpT}$ ensemble at 300,450 , or $600 \mathrm{~K}$ and 1 bar. To properly simulate the olefin diffusion process through a specific 8-ring connecting two adjacent cages A and B, as displayed in Figure 2a, SAPO-34 supercells with 1 or 2 BASs per unit cell were constructed. For the ab initio and force field molecular dynamics (MD) simulations $1 \times 2 \times 1$ and a $2 \times$ $2 \times 2$ supercells were used, respectively (vide infra). Three different models of the 8-ring window were considered for diffusion between adjacent cages, namely with 0 BAS (type 0), 1 BAS (type 1), or 2 BAS (type2) on the 8-ring (see Figure 2c). For type 1, the position of the acid proton was arbitrarily chosen. For type 2 , the two Brønsted acid sites were located in next-nearest-neighbor positions, as suggested in refs 49 and 50. In case of type 0 and type 2 rings, cages A and B are equivalent, while in the case of a type 1 ring, cage $B$ is defined as the cage containing the oxygen atom of the acid site.

2.2. Force Field MD Simulations. Force field MD (FF-MD) simulations are computationally very efficient, but they may fail to accurately describe explicit host-guest interactions (vide infra). One of the advantages of using force fields is that they allow performing MD simulations on a large $2 \times 2 \times 2$ supercell, which reduces any artificial interactions between periodic images of the guest species. Especially in the case of a high loading of the cages, these interactions might have a significant effect. The force fields used in this work were derived according to the procedure outlined in section S3 of the Supporting Information. All FF-MD simulations are performed in the NVT ensemble at 300,450 , and $600 \mathrm{~K}$ using the DL_POLY Classic simulation package (version 1.9). ${ }^{51-53}$ Each simulation spans a total time of 25 ns.

To accelerate sampling of the (hindered) diffusion through the 8ring windows, metadynamics (MTD) simulations ${ }^{54}$ were performed. This technique requires the definition of a reaction coordinate or collective variable (CV) which can uniquely describe the hopping of the guest molecule between cage $\mathrm{A}$ and cage $\mathrm{B}$. In accordance with our earlier work, the $\mathrm{CV}(\xi)$ is defined as the projection of the center of mass of the guest molecule $\left(\vec{r}_{\mathrm{M}}\right.$, onto the ring plane normal $\vec{n}_{\text {plane }}$ (see Figure 2b).

$$
\xi=\left(\vec{r}_{\mathrm{M}}-\vec{r}_{\mathrm{C}}\right) \vec{n}_{\text {plane }}
$$

The vector $\vec{r}_{\mathrm{C}}$ represents the positioning vector of the ring center. The value of the $\mathrm{CV}$ reaches 0 when the center of mass of the olefin 

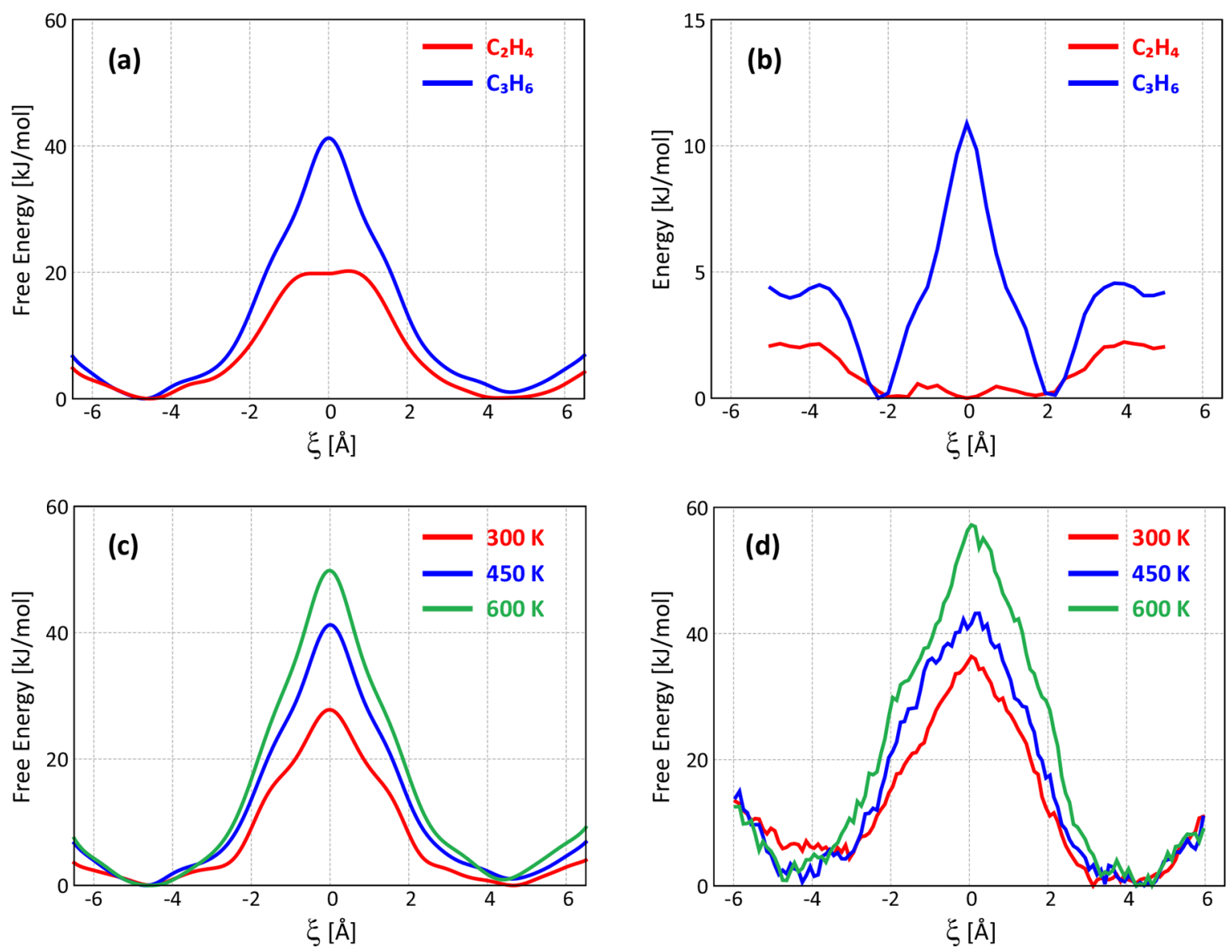

Figure 3. (a) Free energy profiles for ethene/propene diffusion through a type 0 ring of H-SAPO-34 from FF-MTD simulations at $450 \mathrm{~K}$. (b) Average (nonbonding) interaction energy profiles for ethene/propene diffusion through a type 0 ring of H-SAPO-34 at $450 \mathrm{~K}$. (c) Free energy profiles for propene diffusion through a type 0 ring of H-SAPO-34 at different temperatures from FF-MTD simulations. (d) Free energy profiles for propene diffusion through a type 0 ring of H-SAPO-34 at different temperatures from AI-US simulations.

crosses the plane of the 8 -ring. In the case of type 0 and type 2 diffusion, there is no clear distinction between cages $\mathrm{A}$ and $\mathrm{B}$, while in the case of type 1 diffusion, the positive region of the reaction coordinate $\xi$, which we assume to be cage $\mathrm{B}$, is unambiguously determined by the position of the oxygen of the acid site.

Free energy profiles were obtained by averaging over 10 independent simulations with different initial configurations. To prevent the diffusion of the guest molecules to a nearby cage $\mathrm{C}$, parabolic constraints were imposed to the simulations. First, the collective variable was restricted to the range $-9.0 \AA$ to $+9.0 \AA$ to allow the diffusing molecule to jump only between the adjacent cages $\mathrm{A}$ and $\mathrm{B}$. Also, the distance between the center of mass of additional guest molecules and the center of the cage was limited to a maximum distance of $8 \AA$ to ensure that each spectator molecule remains in its original cage.

2.3. Ab Initio MD Simulations. Ab initio MD (AI-MD) simulations yield an improved description of host-guest interactions, although at higher computational cost. Therefore, a $1 \times 2 \times 1$ supercell was employed for the first-principles simulations. All AI-MD simulations were performed in the NVT ensemble at the revPBE-D3 level of theory ${ }^{55}$ using the $\mathrm{CP} 2 \mathrm{~K}$ package. The total simulation time consisted of a production run of $100 \mathrm{ps}$ after $10 \mathrm{ps}$ of equilibration. During the MD simulations, a $\pi-\mathrm{H}$ interaction between the acid proton and the $\pi$-electrons from the double bond of the alkene can be formed. To identify this state, the following empirical distance criterion needs to be obeyed. If the distances between the acid proton and the double-bond carbon atoms are both smaller than $2.85 \AA$, an alkene $\pi$-complex was sampled, otherwise a purely dispersion governed interaction state was sampled. ${ }^{56}$
To construct (free) energy profiles for the diffusion through the 8rings, umbrella sampling (US) simulations ${ }^{57}$ were performed. Constraints similar to those for the FF-MTD simulations were added to prevent the diffusion to other nearby cages. More information on the computational details is given in section S3 of the Supporting Information. An overview of all simulations performed in this work can be found in Table S1.

\section{RESULTS AND DISCUSSION}

\subsection{Influence of Temperature on Diffusion Behavior.}

First, the influence of temperature on the ethene and propene diffusion through the H-SAPO-34 zeolite pore system is studied. To this end, cage A is loaded with ethene or propene, which would in principle be able to diffuse into cage B through the 8-ring during a regular MD simulation. As ethene (kinetic diameter of $390 \mathrm{pm}$ ) is a relatively small molecule with respect to the size of the 8-ring window, multiple crossings between cage $\mathrm{A}$ and cage $\mathrm{B}$ were observed during a regular FF-MD simulation. The free energy profiles of ethene diffusion through a type 0 ring can be quite accurately derived from regular MD simulations, as evidenced by Figure S3, showing a comparison between the free energy profiles from both regular and enhanced $\mathrm{MD}$ simulations. In the case of propene (kinetic diameter of $450 \mathrm{pm}$ ), no window crossings are observed in regular MD simulations. This clearly underlines that propene diffusion is a hindered process in small pore zeolites. Therefore, in the remainder of this paper, enhanced sampling 

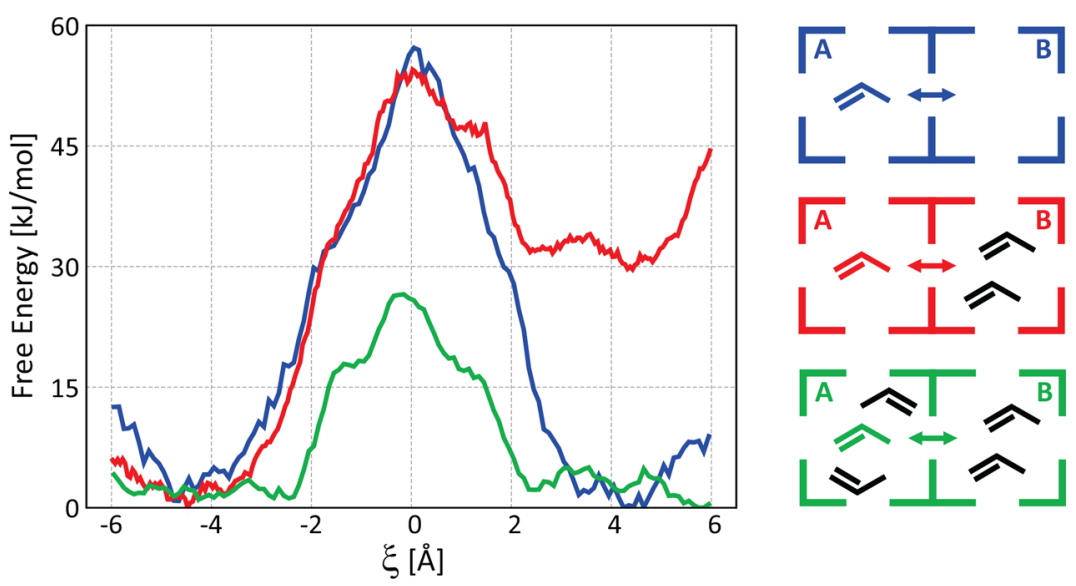

Figure 4. Free energy profiles for propene diffusion through a type 0 ring of H-SAPO-34 at $600 \mathrm{~K}$ with different propene loadings in the cages from AI-US simulations.

MD techniques (see sections 2.2 and 2.3) will be applied to obtain the diffusion barriers.

The free energy profiles for ethene and propene diffusion through ring type 0 (without BAS) at $450 \mathrm{~K}$ from FF-MTD simulations are shown in Figure 3a. The lower free energy barrier for ethene diffusion $(21.2 \mathrm{~kJ} / \mathrm{mol})$ in comparison to propene diffusion $(40.9 \mathrm{~kJ} / \mathrm{mol})$ can obviously be associated with the smaller size of the ethene molecule. Additionally, to disentangle the enthalpy and entropy contributions to the free energy, we plot in Figure $3 \mathrm{~b}$ the average (nonbonding) interaction energy profile for both ethene and propene diffusion. The energetic contribution to the diffusion barrier for ethene is almost zero, resulting in a purely entropic barrier. For propene, the free energy diffusion barrier consists of both a (small) energetic $(11 \mathrm{~kJ} / \mathrm{mol})$ and an entropic contribution $(29.9 \mathrm{~kJ} / \mathrm{mol})$ at $450 \mathrm{~K}$. The entropy contribution to the overall barrier (see Table S5) is positive and increases substantially with temperature (from $19.1 \mathrm{~kJ} / \mathrm{mol}$ at $300 \mathrm{~K}$ to $37.7 \mathrm{~kJ} / \mathrm{mol}$ at $600 \mathrm{~K}$ ), as propene diffusion through the small 8-ring windows is unfavorable. This trend was already predicted from MD simulations of ethane in the LTA zeolite by Schüring et al. ${ }^{58}$ Furthermore, we analyzed the fluctuation of the ring surface as a function of the collective variable $\xi$ (see Figure S7), which shows that the expansion of the 8-ring of SAPO-34 upon diffusion is clearly larger in the case of propene.

The temperature effect on the diffusivity of propene through 8 -ring type 0 is shown in Figure $3 \mathrm{c}$ and Table S5. The absolute free energy barrier increases from $27.8 \mathrm{~kJ} / \mathrm{mol}$ at $300 \mathrm{~K}$ to 40.9 and $49.4 \mathrm{~kJ} / \mathrm{mol}$ at 450 and $600 \mathrm{~K}$, respectively. However, the diffusion barrier in units of $k_{\mathrm{B}} T$ slightly decreases in terms of temperature. Since the probability of propene being at the center of the 8-ring $(\xi=0)$ is expressed by the Boltzmann factor, $e^{-\Delta F^{\ddagger} / k_{B} T}$, the overall diffusivity thus increases with temperature, as expected. At high temperature, guest molecules will be more mobile in the large cages, resulting in an increased probability to find propene in the 8-ring corresponding to intercage migration. In spite of the larger absolute free energy barriers, the overall diffusivity will increase for rising temperatures because the kinetic energy of the guest molecules will also increase, which is reflected by the decreasing free energy barriers in $k_{\mathrm{B}} T$ units (see Table S5).

At this point, it is interesting to assess if these general trends are described correctly by the force field based simulations. To check the accuracy of the FF-MTD results, ab initio umbrella sampling simulations are performed for the 8-ring type 0 diffusion of propene. The constructed free energy profiles for the three temperatures are shown in Figure $3 \mathrm{~d}$. While the qualitative trends are preserved, the quantitative values of the free energy barriers are quite sensitive to the applied level of theory. Using the DFT approach, the free energy barriers are $5-10 \mathrm{~kJ} / \mathrm{mol}$ higher in comparison to the force field approach (see Table S1). The force field based method may be used to assess general diffusivity trends, but performing a quantitative assessment of the diffusion process might be less reliable. Therefore, in the remainder of this paper, where we assess the importance of additional guest molecules in the cages on the diffusivity, we opted to only perform DFT-based enhanced sampling MD simulations.

3.2. Influence of Propene Loading on the Diffusion Behavior. To assess the effect of ethene and propene diffusivity on the MTO process, it is essential to increase the hydrocarbon loading of the catalyst in order to mimic the true MTO conditions. In this part, we assess the influence of additional propene molecules, as reaction products diffusing out of the catalyst, in the cages of H-SAPO-34 on the diffusivity. Using a thermodynamic model developed in house, ${ }^{59}$ which is based on the propene adsorption energy and accessible free pore volume, we determined that the maximum occupation of the H-SAPO-34 pore system is four propene molecules per cage, as outlined in section S11 of the Supporting Information. A series of regular MD simulations were performed with a varying propene loading in the cages of H-SAPO-34 and without acid sites in the 8-ring. When we start with three or four propene molecules in a cage, spontaneous diffusion of one propene molecule to an adjacent cage is observed very quickly with a finite lifetime of less than $1 \mathrm{~ns}$ before the first propene molecule exits the loaded cage.

Normally one may expect that intermolecular interactions are much better described using an ab initio instead of an atomic force field description. Therefore, to determine the free energy barrier for propene diffusion through a type 0 ring from cage A to cage $B$ with various propene loadings, we performed a series of AI-US simulations. Additional constraints were imposed to ensure that the extra propene molecules remain adsorbed in the same cage. Figure 4 shows the resulting free energy profiles for three different propene loading configurations. In the case of two propene molecules in cage B the 

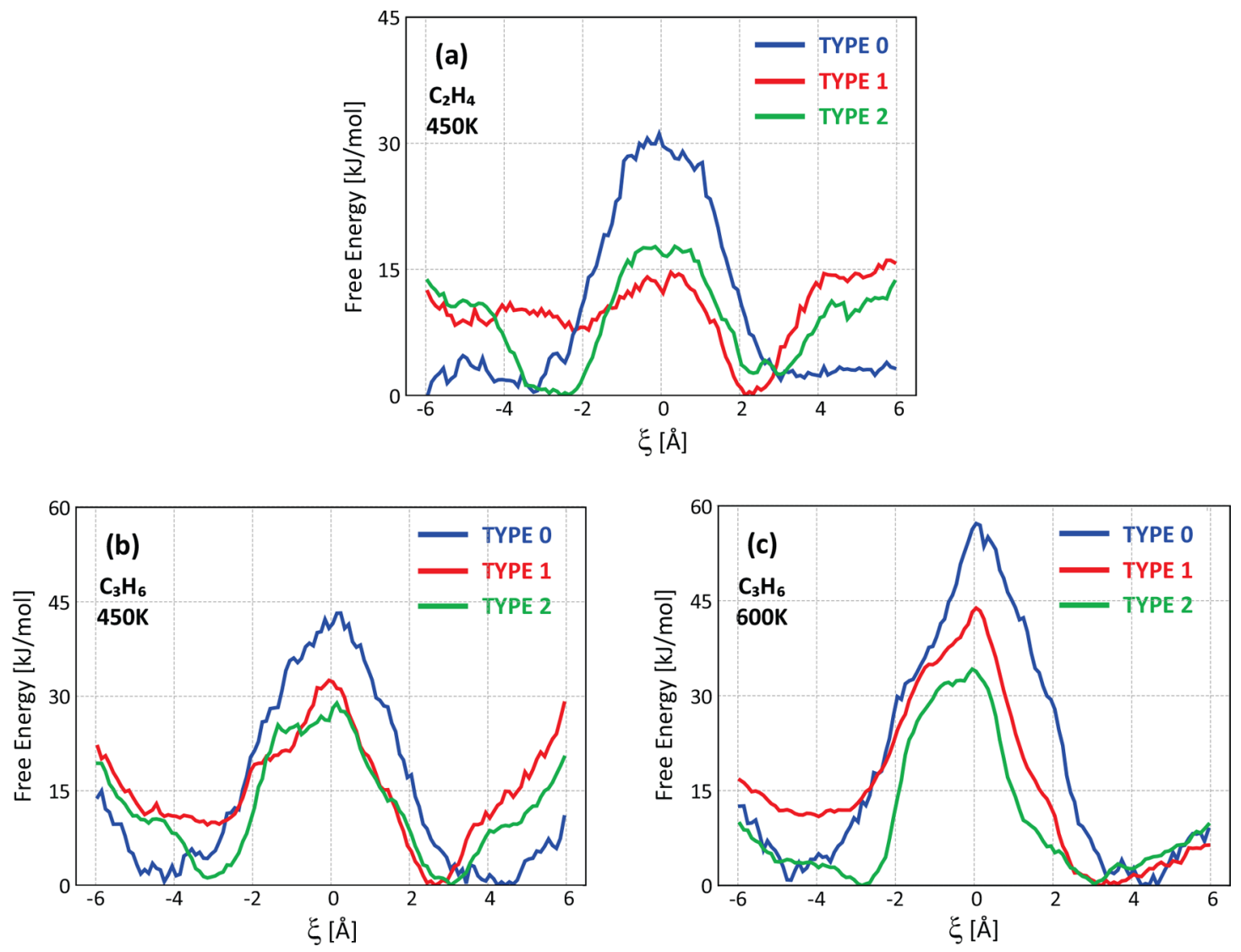

Figure 5. Free energy profiles for (a) ethene diffusion at $450 \mathrm{~K}$, (b) propene diffusion at $450 \mathrm{~K}$, and (c) propene diffusion at $600 \mathrm{~K}$ through the different ring types of H-SAPO-34 from AI-US simulations.

forward diffusion barrier is hardly affected (less than $4 \mathrm{~kJ} /$ mol). However, the backward diffusion barrier, i.e., diffusion from a cage with three propene molecules to an empty cage, is substantially decreased due to the lower stability and reduced configurational freedom in cages with a higher propene loading. The diffusion barrier is lowered by nearly $20 \mathrm{~kJ} / \mathrm{mol}$ in comparison to the reference case in the absence of additional propene molecules. For the highest loading, two additional propene molecules in both cage $\mathrm{A}$ and cage $\mathrm{B}$, the diffusion barrier is also significantly lowered (ca. $15 \mathrm{~kJ} / \mathrm{mol}$ ). In summation, the presence of additional spectator molecules in the H-SAPO-34 cages increases the diffusion rate of propene.

For the sake of completeness, we also performed FF-MTD simulations at six different loading configurations. These results are displayed in Figure S11 of the Supporting Information and confirm the importance of a good description of the intermolecular interactions. This difference is best illustrated for the configuration with the highest propene loading $\left(\mathrm{A}, 3 \mathrm{C}_{3}{ }^{=} ; \mathrm{B}, 2 \mathrm{C}_{3}{ }^{=}\right)$, which shows a reduction of the barrier by ca. $30 \mathrm{~kJ} / \mathrm{mol}$ in the ab initio model while this value is barely $15 \mathrm{~kJ} / \mathrm{mol}$ with the FF model in comparison to the reference case.

3.3. Influence of Brønsted Acid Sites on the Diffusion Behavior. To investigate the effect of the presence of BASs in the 8-ring window, first the diffusion of propene through the various ring types was studied at 300, 450, and $600 \mathrm{~K}$ using FFMTD simulations (see Figure S4) on H-SAPO-34 without additional loading of the cages. The general diffusion trends with varying temperature (cf. section 3.1) are almost independent of the ring type, which is rather surprising, as one would expect that guest interactions with the BAS sites will affect the diffusion behavior. This observation indicates that the force field based simulations yield an improper description of the molecular interactions between the Brønsted acidic sites and the olefins. Therefore, to properly account for the adsorption and diffusion behavior of olefins in the presence of BASs, it is essential to describe the host-guest interactions using first-principles techniques, which are computationally more expensive.

Figure 5 shows the free energy profiles for light olefin diffusion at 450 and $600 \mathrm{~K}$ from first-principles umbrella sampling simulations. The presence of acid sites clearly influences the free energy barrier. For both ethene and propene, the highest diffusion barriers are predicted for ring type 0 : i.e., in the absence of acid sites in the 8-ring. For ring type 1 ( 1 BAS) and ring type 2 (2 BASs), significantly lower barriers are obtained. A barrier of about $30 \mathrm{~kJ} / \mathrm{mol}$ is found for ethene diffusion from cage $\mathrm{B}$ to cage $\mathrm{A}$ through ring type 0 . The barrier is lowered to about $15 \mathrm{~kJ} / \mathrm{mol}$ for ethene diffusion through an 8-ring with acid sites. The lowering of the diffusion barrier in the presence of BASs can be understood by analyzing the specific interaction of the olefins with the BAS. To this end, we first determined the adsorption energies of ethene and propene near the 8-ring windows with a varying number of acid sites using static DFT calculations. The results are given in Table 1, and the optimized configurations are shown in section S4 of the Supporting Information. Evidently, the lowest adsorption strength is found for the cage without acid sites, as no stabilizing $\pi$-complex interaction can be formed. For 
Table 1. Electronic Adsorption Energies for Ethene and Propene in H-SAPO-34 Cages near an 8-Ring with 0, 1, or 2 Brønsted Acid Sites

\begin{tabular}{lcccc} 
& \multicolumn{4}{c}{$\Delta E_{\text {ads }}(\mathrm{kJ} / \mathrm{mol})$} \\
\cline { 2 - 5 } & type 0 & type 1, cage B & type 1, cage A & type 2 \\
ethene & -24.2 & -57.6 & -59.2 & -73.2 \\
propene & -46.8 & -71.8 & -73.9 & -91.8 \\
\hline
\end{tabular}

adsorption of the olefin in a cage with a type 1 ring, two minima were identified with the alkene positioned in either cage A or cage B. In both cages, the alkene can interact with the acid proton, forming a $\pi$-complex, with similar adsorption energies for both configurations. The strongest adsorption is found for ring type 2 , in which the double bond of the olefin can undergo a double $\pi$-complex interaction with both BASs. The absolute values for the adsorption energies might be rather sensitive to the level of theory, as discussed in more detail in ref 60 .

As the adsorption of alkenes in acidic zeolites is a dynamic process, alkenes will move rather freely across the cages of the zeolite and reside closely to the acid site only for a finite time fraction before desorbing again. From time to time, the olefin will cross the high diffusion barrier and hop between neighboring cages. Such effects have already been observed for alkenes and other adsorbates. ${ }^{56,61-63}$ To gain more insight into the mobility of the olefins and the dynamic character of the adsorption process, a series of DFT-based AI-MD simulations were performed at 450 and $600 \mathrm{~K}$ with ethene or propene initially located in cage B. For ring type 0 , i.e., without acid sites on the ring, there is no driving force to keep the alkene in the neighborhood of the 8-ring. The olefins are only stabilized by weak dispersion interactions with the wall of the zeolite cages. Therefore, the olefin will reside on average at a larger distance from the 8-ring, thus resulting in the highest barriers for diffusion.

The presence of acid sites clearly facilitates the hopping process between cages, as a favorable olefin $\pi-\mathrm{H}$ interaction complex with the BAS can be formed during the transition. ${ }^{56,61}$ The guest olefin will also simply be stabilized by forming a $\pi$ complex near the type 1 or type 2 ring without crossing the 8 ring window. If one acid site is present on the 8-ring, this $\pi$ complex configuration is sampled during $50 \%$ and $75 \%$ of the total simulation time for ethene and propene, respectively. If the 8-ring contains two acid sites, the lifetime of the olefin $\pi$ complexes increases even further, for ethene up to $60 \%$ and for propene up to $85 \%$ of the simulation time (see Figure S6 in the Supporting Information). As a result, the olefin will on average be positioned more closely to the 8-ring and diffusion rates will be enhanced by the tendency to form a stable $\pi$-complex interaction. Note that a force field simulation does not succeed in reproducing this feature (Figure S4). At $300 \mathrm{~K}$, the largest barrier is observed for diffusion through a type 1 ring, which is in contradiction with the predictions of the $a b$ initio simulations.

The acid sites influence not only the height of the diffusion barrier but also the shape of the free energy profiles. For ring type 0 , the free energy minima are found at $\xi \approx \pm 4.0 \AA$, while in case of ring types 1 and 2 , free energy minima are encountered at $\xi \approx \pm 2.5 \AA$. which confirms the existence of a stable $\pi-\mathrm{H}$ interaction complex close to the 8-ring window. These minima also correspond to the most sampled regions of the collective variable space in the regular AI-MD simulations (see Figure S5). In the simulations without acid sites, the olefin is preferentially located farther away from the acid site and closer to the walls of the chabazite cages, i.e. between $\xi=4.0 \AA$ and $\xi=6.0 \AA$. In the presence of acid sites, the preferred states can be clearly identified between $\xi=2.0 \AA$ and $\xi=3.0 \AA$.

The free energy profiles for ring types 0 and 2 are nearly symmetrical with respect to the ring center $(\xi=0)$. This can be easily understood, as cage A and cage B are equivalent in the absence of acid sites in the ring. Also in the case of two BASs in the ring, the probabilities of finding an acid proton oriented toward cage A or cage B are also almost equal, thus yielding a nearly symmetrical profile. For ring type 1, a more asymmetrical free energy profile is found in terms of the reaction coordinate, which can be explained by the preference of the acid proton for a specific cage, although at higher temperature $(600 \mathrm{~K})$ the asymmetrical pattern is less pronounced. From regular AI-MD simulations, we find that the probability to find the acid proton in cage $\mathrm{B}$ is significantly larger than that in cage $A$ for an empty framework, corresponding to a $63 \% / 37 \%$ ratio. If an alkene is adsorbed in cage B, this ratio is even higher (see also sections S7 and S9 in the Supporting Information). Consequently, the existence of beneficial $\pi-\mathrm{H}$ interactions favors olefin adsorption in cage $\mathrm{B}$. Diffusion from cage A to cage B has a lower activation $(7 \mathrm{~kJ} /$ mol for ethene diffusion), as it allows the formation of a stabilizing $\pi$-complex upon entering into cage B. Likewise, diffusion from cage B to cage A has a higher activation $(15 \mathrm{~kJ} /$ mol for ethene diffusion), as it requires the breaking of this $\pi$ complex interaction. The same feature is observed for propene. At $450 \mathrm{~K}$, the forward diffusion barrier is about $10 \mathrm{~kJ} / \mathrm{mol}$ lower. Even at the operating temperature $(600 \mathrm{~K})$ this asymmetry holds.

3.4. Diffusion in a Complex Environment with Hydrocarbon Pool Species and Methanol Molecules. Under MTO operating conditions, there are barely any empty cages in the H-SAPO-34 catalyst. Instead, many cages are filled with hydrocarbon pool species or other protic molecules such as water and methanol. To assess the effect of this more realistic MTO environment, a series of first-principles-based umbrella sampling simulations on propene diffusion at $650 \mathrm{~K}$ through a type 18 -ring in the presence of different hydrocarbon pool species have been carried out. In a first simulation, propene diffusion from cage A, filled with additional methanol molecules, into cage $\mathrm{B}$, filled with hexamethylbenzene (HMB) and extra methanol molecules, is considered. In a second simulation, cage B is filled with toluene (TOL) and methanol molecules. Additional constraints were imposed to prevent immediate diffusion of methanol molecules out of cage B toward cage A.

Figure 6 visualizes the resulting free energy profiles for both cases. Due to the presence of hydrocarbon pool species and methanol, the free energy profile is no longer a bell-shaped curve but a strongly distorted and asymmetric profile. The maximum of the free energy profile is no longer situated at the ring center $(\xi=0)$, but in cage $B$, at much greater distances from the 8-ring window, indicating the strong resistance for propene to enter a cage which is already filled with an HP species.

The discrepancy between both free energy profiles for cage A $(\xi<0)$ might be explained by the presence of methanol, which results in a more complex energy surface. In the case of $\mathrm{HMB}$, a minimum is encountered in cage $\mathrm{A}$ at $\xi \approx-2.5 \AA$ from the ring mouth (Figure $7 \mathrm{a}$ ). In cage $\mathrm{B}$, no clear energetic 

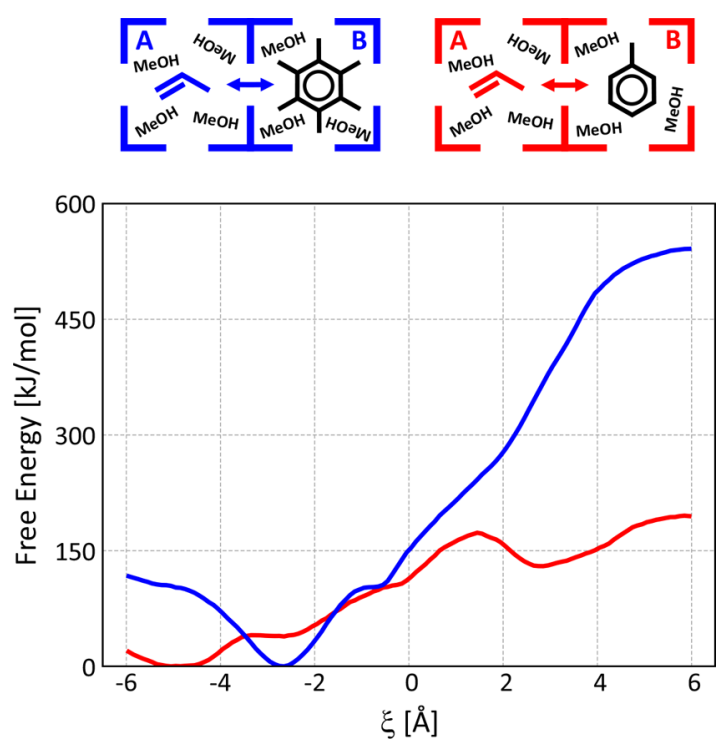

Figure 6. Free energy profile for propene diffusion through an 8-ring type 1 of H-SAPO-34 at $650 \mathrm{~K}$ from AI-US simulations. Cage B contains a hydrocarbon pool species (hexamethylbenzene (HMB) or toluene (TOL)). Both cages have additional methanol loading.

minimum can be identified; instead, a strongly repulsive wall is observed for propene to enter cage B. We can conclude that a propene molecule that would be formed in cage B would be immediately expelled to a neighboring cage, provided this cage is not blocked by another HP species. In the case of toluene, also a relatively large barrier is observed for propene to enter the cage; however, the mobility of propene is still relatively high in the cage with toluene (cf. Figure S10). For TOL, two local minima are found in cage $\mathrm{A}$ at $\xi \approx-5.0 \AA$ and $\xi \approx-2.5$ $\AA$ (Figure $7 \mathrm{~b}$ ). In contrast to $\mathrm{HMB}$, also a clear minimum for the coexistence of propene and toluene in cage $\mathrm{B}$ can be recognized at $\xi \approx 2.5 \AA$ (Figure $7 \mathrm{c}$ ). To check the validity of this diffusion behavior, regular AI-MD simulations at $650 \mathrm{~K}$ are carried out on an initial configuration where propene and toluene/hexamethylbenzene (next to a loading of additional methanol molecules) are both located in cage B. These simulations show that, in the presence of $\mathrm{HMB}$, propene diffuses immediately to a neighboring cage. In the presence of toluene, however, propene remains adsorbed in the same cage for at least $80 \mathrm{ps}$, thus confirming the existence of a stable minimum. Nevertheless, the free energies of propene and toluene coadsorbed in the same cage are much higher than those when both species are adsorbed in separate cages. In summary, if ethene and propene are formed in cages containing a HP species, they will easily diffuse to the next cage, provided this cage is not filled with another bulky HP species. In this case, ethene and propene would become completely stuck, ultimately leading to catalyst deactivation. This discussion is in agreement with the findings of Gallego et

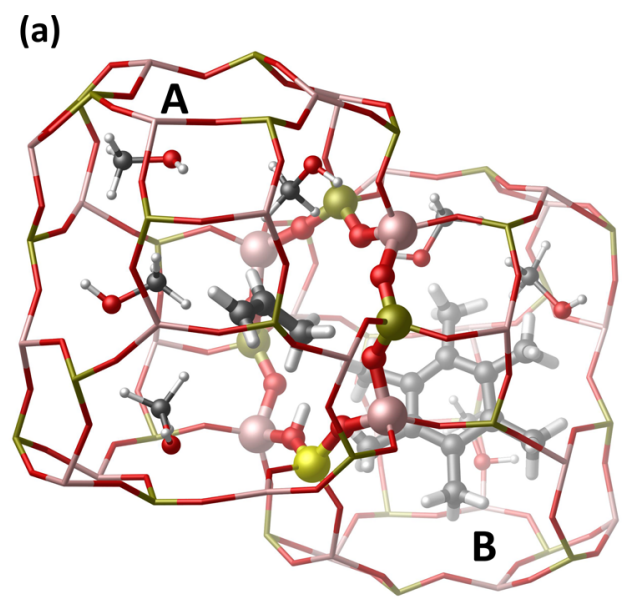

(b)

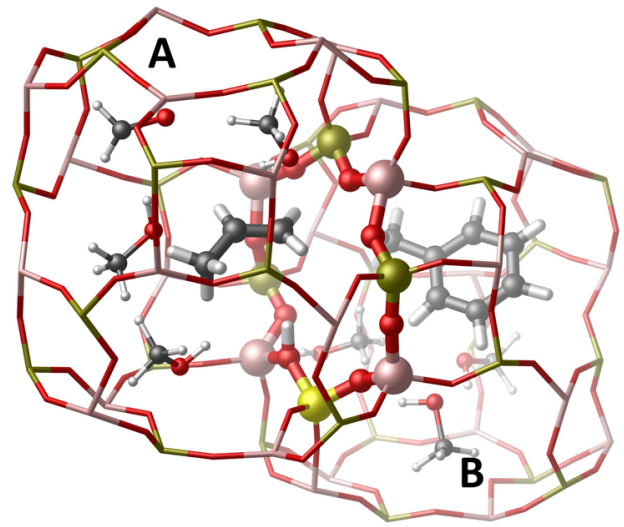

(c)

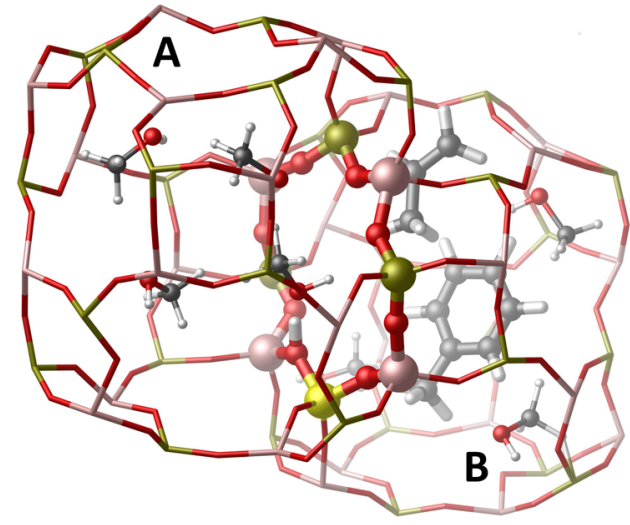

Figure 7. Snapshots from the regular AI-MD simulations at $650 \mathrm{~K}$ of the local minima on the free energy surface corresponding to (a) propene adsorbed in cage A $(\xi=-2.5 \AA)$ and hexamethylbenzene in cage B, (b) propene adsorbed in cage A $(\xi=-2.5 \AA)$ and toluene in cage B, and (c) propene and toluene coadsorbed in cage B $(\xi=+2.5 \AA)$, next to additional methanol loading. 
al., who investigated the catalyst performance for a varying distribution of BASs within the zeolite framework as well as the deactivation of the zeolite (H-SSZ-13 with the same topology of H-SAPO-34), where the presence of empty cages prevents catalyst clogging. ${ }^{64}$ Note that the same exercise could be performed in a similar way with ethene instead of propene. An analogous qualitative behavior is expected for ethene diffusion, although with significantly lower barriers.

\section{CONCLUSIONS}

Light olefin diffusion through the pores of an H-SAPO-34 zeolite is an extremely complex event, which is affected by several aspects such as process conditions (temperature), catalyst loading, acid strength, and acid site density. Obtaining insight into all these factors imposes a considerable challenge. In this work, we studied the diffusion of ethene and propene through the 8-ring windows of H-SAPO-34 at the molecular level for a series of settings which are representative of typical methanol-to-olefins reaction conditions. The diffusion of alkenes through the zeolite cages is an activated process; hence, enhanced sampling molecular dynamics techniques were required to properly sample all regions of the diffusional phase space. The influence of external variables such as temperature could be investigated with force field simulations on large supercells. However, to study the effect of acid sites on the diffusion of light olefins, a first-principles-based description was necessary to properly account for all molecular interactions. To the best of our knowledge, such a combined enhanced sampling and first-principles approach for hindered diffusion in zeolites has not been applied in earlier studies. As expected, the diffusion process is more hindered for propene than for ethene. At higher temperatures, the diffusivity increases, as the free energy barrier is mainly affected by entropic factors. A higher propene loading also enhances the diffusivity through the cage windows due to the reduced conformational freedom and mobility. The free energy profiles from ab initio DFT simulations clearly show the impact of BASs on the olefin diffusion rates. In general, the presence of Brønsted acid sites in the 8-ring substantially lowers the diffusion barriers for propene and ethene, thanks to the formation of favorable $\pi-\mathrm{H}$ interactions between the olefin double bond and the Brønsted acid site. On the other hand, aromatic hydrocarbon pool species can severely clog the pore system. The nature of the HP species substantially affects the diffusivity. The barrier for propene to enter a cage with a trapped hexamethylbenzene species is very high, and in general, once formed, propene would quickly diffuse out of such a cage to neighboring cages, provided they are not filled with bulky HP species. In the case of toluene, however, the passage of propene might not be fully excluded.

This study yields unprecedented insights into how various molecular characteristics may affect the hindered diffusion of light olefins through the 8-ring windows of H-SAPO-34. The methodology presented here could be extended to study on a systematic basis the influence of other important factors under operating conditions, such as an increasing water content or varying methanol loadings. It should be stressed that the selectivity may be the result of a complex interplay among various factors related to stabilization of specific intermediates, intrinsic reactivity, and transport phenomena. Herein we isolated only a few aspects which might contribute to the overall product yield of the MTO process in H-SAPO-34. The importance of the spatiotemporal behavior of the catalytic system should also be underlined, as catalyst aging might seriously affect the diffusivity. Early in the catalyst lifetime only a small fraction of the zeolite pores may be filled with aromatic hydrocarbon pool species. As time on stream increases, more bulky species such as fully methylated polymethylbenzenes but also more aged species such as phenanthrene will appear, which can put severe restrictions on the mass transport. $2,22,24,25$ This might be one of the factors explaining the change in product selectivity with time on stream. Our study shows that the acid site density significantly affects the diffusivity; however, it should be kept in mind that a higher acid site density will also enhance the formation and growth of aromatic hydrocarbon pool species. Trapped olefins which have difficulties in propagating through the catalyst may enhance the formation of large polyaromatic species. Finally, the influence of diffusion on the product distribution might be intertwined with the operation of different catalytic cycles.

\section{ASSOCIATED CONTENT}

\section{Supporting Information}

The Supporting Information is available free of charge at https://pubs.acs.org/doi/10.1021/jacs.9b10249.

Overview of diffusion barriers, additional computational details of the force field and ab initio simulations, adsorption energies from static calculations, comparison of regular MD and MTD, structural analysis from regular $\mathrm{MD}$ for different ring types, ring expansion, proton mobility, thermodynamic model for propene loading, and diffusion profiles for various propene loadings (PDF)

\section{AUTHOR INFORMATION}

\section{Corresponding Author}

Veronique Van Speybroeck - Center for Molecular Modeling, Ghent University, 9052 Zwijnaarde, Belgium; 이이.org/ 0000-0003-2206-178X; Email: Veronique.vanspeybroeck@ ugent.be

\section{Authors}

Pieter Cnudde - Center for Molecular Modeling, Ghent University, 9052 Zwijnaarde, Belgium; 이이.org/00000002-6735-0078

Ruben Demuynck - Center for Molecular Modeling, Ghent University, 9052 Zwijnaarde, Belgium; (1) orcid.org/00000003-3475-8808

Steven Vandenbrande - Center for Molecular Modeling, Ghent University, 9052 Zwijnaarde, Belgium

Michel Waroquier - Center for Molecular Modeling, Ghent University, 9052 Zwijnaarde, Belgium

German Sastre - Instituto de Tecnologia Quimica, UPV-CSIC Universidad Politecnica de Valencia, 46022 Valencia, Spain; (1) orcid.org/0000-0003-0496-6331

Complete contact information is available at:

https://pubs.acs.org/10.1021/jacs.9b10249

\section{Author Contributions}

${ }^{\S}$ P.C. and R.D. contributed equally.

\section{Notes}

The authors declare no competing financial interest. 


\section{ACKNOWLEDGMENTS}

P.C., R.D., S.V., and V.V.S. acknowledge funding from the European Research Council under the ERC Grant Agreement 240483 and the European Union's Horizon 2020 research and innovation programme (Consolidator ERC Grant Agreement 647755 - DYNPOR). G.S. thanks the Ministerio de Economia $\mathrm{y}$ Competitividad of Spain for the provision of funding through projects "Severo Ochoa" (SEV-2016-0683), CTQ2015-70126$\mathrm{R}$, and ASIC-UPV for computing time. The computational resources in this work were provided by the VSC (Flemish Supercomputer Center), funded by the Hercules foundation and the Flemish Government-department EWI.

\section{REFERENCES}

(1) Yarulina, I.; Chowdhury, A. D.; Meirer, F.; Weckhuysen, B. M.; Gascon, J. Recent Trends and Fundamental Insights in the Methanolto-Hydrocarbons Process. Nat. Catal. 2018, 1, 398-411.

(2) Hemelsoet, K.; Van der Mynsbrugge, J.; De Wispelaere, K.; Waroquier, M.; Van Speybroeck, V. Unraveling the Reaction Mechanisms Governing Methanol-to-Olefins Catalysis by Theory and Experiment. ChemPhysChem 2013, 14, 1526-1545.

(3) Van Speybroeck, V.; De Wispelaere, K.; Van der Mynsbrugge, J.; Vandichel, M.; Hemelsoet, K.; Waroquier, M. First Principle Chemical Kinetics in Zeolites: The Methanol-to-Olefin Process as a Case Study. Chem. Soc. Rev. 2014, 43, 7326-7357.

(4) Olsbye, U.; Svelle, S.; Bjørgen, M.; Beato, P.; Janssens, T. V. W.; Joensen, F.; Bordiga, S.; Lillerud, K. P. Conversion of Methanol to Hydrocarbons: How Zeolite Cavity and Pore Size Controls Product Selectivity. Angew. Chem., Int. Ed. 2012, 51, 5810-5831.

(5) Tian, P.; Wei, Y.; Ye, M.; Liu, Z. Methanol to Olefins (MTO): From Fundamentals to Commercialization. ACS Catal. 2015, 5, 1922-1938.

(6) Yarulina, I.; De Wispelaere, K.; Bailleul, S.; Goetze, J.; Radersma, M.; Abou-Hamad, E.; Vollmer, I.; Goesten, M.; Mezari, B.; Hensen, E. J. M.; Martinez-Espin, J. S.; Morten, M.; Mitchell, S.; Perez-Ramirez, J.; Olsbye, U.; Weckhuysen, B. M.; Van Speybroeck, V.; Kapteijn, F.; Gascon, J. Structure-Performance Descriptors and the Role of Lewis Acidity in the Methanol-to-Propylene Process. Nat. Chem. 2018, 10, 804-812.

(7) Svelle, S.; Joensen, F.; Nerlov, J.; Olsbye, U.; Lillerud, K.-P.; Kolboe, S.; Bjørgen, M. Conversion of Methanol into Hydrocarbons over Zeolite H-ZSM-5: Ethene Formation Is Mechanistically Separated from the Formation of Higher Alkenes. J. Am. Chem. Soc. 2006, 128, 14770-14771.

(8) Svelle, S.; Olsbye, U.; Joensen, F.; Bjørgen, M. Conversion of Methanol to Alkenes over Medium- and Large-Pore Acidic Zeolites: Steric Manipulation of the Reaction Intermediates Governs the Ethene/Propene Product Selectivity. J. Phys. Chem. C 2007, 111, 17981-17984.

(9) Hereijgers, B. P. C.; Bleken, F.; Nilsen, M. H.; Svelle, S.; Lillerud, K.-P.; Bjørgen, M.; Weckhuysen, B. M.; Olsbye, U. Product Shape Selectivity Dominates the Methanol-to-Olefins (MTO) Reaction over H-SAPO-34 Catalysts. J. Catal. 2009, 264, 77-87.

(10) Kang, J. H.; Alshafei, H. F.; Zones, S. I.; Davis, M. E. CageDefining Ring: A Molecular Sieve Structural Indicator for Light Olefin Product Distribution from the Methanol-to-Olefins Reaction. ACS Catal. 2019, 9, 6012-6019.

(11) Liang, J.; Li, H.; Zhao, S.; Guo, W.; Wang, R.; Ying, M. Characteristics and Performance of SAPO-34 Catalyst for Methanolto-Olefin Conversion. Appl. Catal. 1990, 64, 31-40.

(12) Arora, S. S.; Nieskens, D. L. S.; Malek, A.; Bhan, A. Lifetime Improvement in Methanol-to-Olefins Catalysis over Chabazite Materials by High-Pressure H 2 Co-Feeds. Nat. Catal. 2018, 1, 666-672.

(13) Nieskens, D. L. S.; Lunn, J. D.; Malek, A. Understanding the Enhanced Lifetime of SAPO-34 in a Direct Syngas-to-Hydrocarbons Process. ACS Catal. 2019, 9, 691-700.
(14) Dahl, I. M.; Kolboe, S. On the Reaction Mechanism for Hydrocarbon Formation from Methanol over SAPO-34: I. Isotopic Labeling Studies of the Co-Reaction of Ethene and Methanol. J. Catal. 1994, 149, 458-464.

(15) Dahl, I. M.; Kolboe, S. On the Reaction Mechanism for Hydrocarbon Formation from Methanol over SAPO-34: II. Isotopic Labeling Studies of the Co-Reaction of Propene and Methanol. J. Catal. 1996, 161, 304-309.

(16) Hemelsoet, K.; Nollet, A.; Vandichel, M.; Lesthaeghe, D.; Van Speybroeck, V.; Waroquier, M. The Effect of Confined Space on the Growth of Naphthalenic Species in a Chabazite-Type Catalyst: A Molecular Modeling Study. ChemCatChem 2009, 1, 373-378.

(17) Brogaard, R. Y.; Weckhuysen, B. M.; Nørskov, J. K. Guest-Host Interactions of Arenes in H-ZSM-5 and Their Impact on Methanolto-Hydrocarbons Deactivation Processes. J. Catal. 2013, 300, 235241.

(18) Bjørgen, M.; Olsbye, U.; Kolboe, S. Coke Precursor Formation and Zeolite Deactivation: Mechanistic Insights from Hexamethylbenzene Conversion. J. Catal. 2003, 215, 30-44.

(19) Dai, W.; Wang, X.; Wu, G.; Li, L.; Guan, N.; Hunger, M. Methanol-to-Olefin Conversion Catalyzed by Low-Silica AlPO-34 with Traces of Brønsted Acid Sites: Combined Catalytic and Spectroscopic Investigations. ChemCatChem 2012, 4, 1428-1435.

(20) Dai, W.; Wang, X.; Wu, G.; Guan, N.; Hunger, M.; Li, L. Methanol-to-Olefin Conversion on Silicoaluminophosphate Catalysts: Effect of Brønsted Acid Sites and Framework Structures. ACS Catal. 2011, 1, 292-299.

(21) Haw, J. F.; Marcus, D. M. Well-Defined (Supra)Molecular Structures in Zeolite Methanol-to-Olefin Catalysis. Top. Catal. 2005, $34,41-48$.

(22) Haw, J. F.; Song, W.; Marcus, D. M.; Nicholas, J. B. The Mechanism of Methanol to Hydrocarbon Catalysis. Acc. Chem. Res. 2003, 36, 317-326.

(23) Marcus, D. M.; Song, W.; Ng, L. L.; Haw, J. F. Aromatic Hydrocarbon Formation in H-SAPO-18 Catalysts: Cage Topology and Acid Site Density. Langmuir 2002, 18, 8386-8391.

(24) McCann, D. M.; Lesthaeghe, D.; Kletnieks, P. W.; Guenther, D. R.; Hayman, M. J.; Van Speybroeck, V.; Waroquier, M.; Haw, J. F. A Complete Catalytic Cycle for Supramolecular Methanol-to-Olefins Conversion by Linking Theory with Experiment. Angew. Chem., Int. Ed. 2008, 47, 5179-5182.

(25) Lesthaeghe, D.; Van der Mynsbrugge, J.; Vandichel, M.; Waroquier, M.; Van Speybroeck, V. Full Theoretical Cycle for Both Ethene and Propene Formation during Methanol-to-Olefin Conversion in H-ZSM-5. ChemCatChem 2011, 3, 208-212.

(26) Bleken, F.; Bjørgen, M.; Palumbo, L.; Bordiga, S.; Svelle, S.; Lillerud, K.-P.; Olsbye, U. The Effect of Acid Strength on the Conversion of Methanol to Olefins Over Acidic Microporous Catalysts with the CHA Topology. Top. Catal. 2009, 52, 218-228.

(27) Westgård Erichsen, M.; Svelle, S.; Olsbye, U. H-SAPO-5 as Methanol-to-Olefins (MTO) Model Catalyst: Towards Elucidating the Effects of Acid Strength. J. Catal. 2013, 298, 94-101.

(28) Mole, T.; Bett, G.; Seddon, D. Conversion of Methanol to Hydrocarbons over ZSM-5 Zeolite: An Examination of the Role of Aromatic Hydrocarbons Using 13carbon- and Deuterium-Labeled Feeds. J. Catal. 1983, 84, 435-445.

(29) Li, J.; Wei, Y.; Chen, J.; Tian, P.; Su, X.; Xu, S.; Qi, Y.; Wang, Q.; Zhou, Y.; He, Y.; Liu, Z. Observation of Heptamethylbenzenium Cation over SAPO-Type Molecular Sieve DNL-6 under Real MTO Conversion Conditions. J. Am. Chem. Soc. 2012, 134, 836-839.

(30) Westgård Erichsen, M.; Mortén, M.; Svelle, S.; Sekiguchi, O.; Uggerud, E.; Olsbye, U. Conclusive Evidence for Two Unimolecular Pathways to Zeolite-Catalyzed De-Alkylation of the Heptamethylbenzenium Cation. Chem CatChem 2015, 7, 4143-4147.

(31) Hwang, A.; Le, T. T.; Shi, Z.; Dai, H.; Rimer, J. D.; Bhan, A. Effects of Diffusional Constraints on Lifetime and Selectivity in Methanol-to-Olefins Catalysis on HSAPO-34. J. Catal. 2019, 369, 122-132. 
(32) Barger, P. In Zeolites for Cleaner Technologies; Guisnet, M., Gilson, J. P., Eds.; Imperial College Press: 2002; Catalytic Science Series Vol. 3, pp 239-260.

(33) Dahl, I. M.; Wendelbo, R.; Andersen, A.; Akporiaye, D.; Mostad, H.; Fuglerud, T. The Effect of Crystallite Size on the Activity and Selectivity of the Reaction of Ethanol and 2-Propanol over SAPO34. Microporous Mesoporous Mater. 1999, 29, 159-171.

(34) Mores, D.; Stavitski, E.; Kox, M. H. F.; Kornatowski, J.; Olsbye, U.; Weckhuysen, B. M. Space- and Time-Resolved In-Situ Spectroscopy on the Coke Formation in Molecular Sieves: Methanol-to-Olefin Conversion over H-ZSM-5 and H-SAPO-34. Chem. - Eur. J. 2008, 14, $11320-11327$.

(35) Iglesia, E.; Wang, T.; Yu, S. Y. Chain Growth Reactions of Methanol on SAPO-34 and H-ZSM5. Stud. Surf. Sci. Catal. 1998, 119, 527-532.

(36) Chen, D.; Moljord, K.; Holmen, A. A Methanol to Olefins Review: Diffusion, Coke Formation and Deactivation on SAPO Type Catalysts. Microporous Mesoporous Mater. 2012, 164, 239-250.

(37) Dai, W.; Scheibe, M.; Li, L.; Guan, N.; Hunger, M. Effect of the Methanol-to-Olefin Conversion on the PFG NMR Self-Diffusivities of Ethane and Ethene in Large-Crystalline SAPO-34. J. Phys. Chem. C 2012, 116, 2469-2476.

(38) Hedin, N.; DeMartin, G. J.; Roth, W. J.; Strohmaier, K. G.; Reyes, S. C. PFG NMR Self-Diffusion of Small Hydrocarbons in High Silica DDR, CHA and LTA Structures. Microporous Mesoporous Mater. 2008, 109, 327-334.

(39) Kärger, J. Measurement of Diffusion in Zeolites-A Never Ending Challenge? Adsorption 2003, 9, 29-35.

(40) Kärger, J. Comment on "PFG NMR Self-Diffusion of Small Hydrocarbons in High Silica DDR, CHA and LTA Structures" [Micropor. Mesopor. Mater. 109 (2008) 327]. Microporous Mesoporous Mater. 2008, 116, 715-717.

(41) Li, C.; Paris, C.; Martínez-Triguero, J.; Boronat, M.; Moliner, M.; Corma, A. Synthesis of Reaction-adapted Zeolites as Methanol-toOlefins Catalysts with Mimics of Reaction Intermediates as Organic Structure-directing Agents. Nat. Catal. 2018, 1, 547-554.

(42) Combariza, A. F.; Sastre, G.; Corma, A. Propane/Propylene Diffusion in Zeolites: Framework Dynamics. J. Phys. Chem. C 2009, $113,11246-11253$

(43) Vidoni, A.; Ruthven, D. M. Diffusion of $\mathrm{C}_{2} \mathrm{H}_{6}$ and $\mathrm{C}_{2} \mathrm{H}_{4}$ in DDR Zeolite. Ind. Eng. Chem. Res. 2012, 51, 1383-1390.

(44) Ghysels, A.; Moors, S. L. C.; Hemelsoet, K.; De Wispelaere, K.; Waroquier, M.; Sastre, G.; Van Speybroeck, V. Shape-Selective Diffusion of Olefins in 8-Ring Solid Acid Microporous Zeolites. J. Phys. Chem. C 2015, 119, 23721-23734.

(45) Awati, R. V.; Ravikovitch, P. I.; Sholl, D. S. Efficient and Accurate Methods for Characterizing Effects of Framework Flexibility on Molecular Diffusion in Zeolites: CH4 Diffusion in Eight Member Ring Zeolites. J. Phys. Chem. C 2013, 117, 13462-13473.

(46) García-Sánchez, A.; Dubbeldam, D.; Calero, S. Modeling Adsorption and Self-Diffusion of Methane in LTA Zeolites: The Influence of Framework Flexibility. J. Phys. Chem. C 2010, 114, 15068-15074.

(47) Camp, J. S.; Sholl, D. S. Transition State Theory Methods To Measure Diffusion in Flexible Nanoporous Materials: Application to a Porous Organic Cage Crystal. J. Phys. Chem. C 2016, 120, 11101120.

(48) Katada, N.; Nouno, K.; Lee, J. K.; Shin, J.; Hong, S. B.; Niwa, M. Acidic Properties of Cage-Based, Small-Pore Zeolites with Different Framework Topologies and Their Silicoaluminophosphate Analogues. J. Phys. Chem. C 2011, 115, 22505-22513.

(49) Sastre, G.; Lewis, D. W.; Catlow, C. R. A. Structure and Stability of Silica Species in SAPO Molecular Sieves. J. Phys. Chem. 1996, 100, 6722-6730.

(50) Termath, V.; Haase, F.; Sauer, J.; Hutter, J.; Parrinello, M. Understanding the Nature of Water Bound to Solid Acid Surfaces. Ab Initio Simulation on HSAPO-34. J. Am. Chem. Soc. 1998, 120, 85128516.
(51) Smith, W.; Forester, T. R. DL POLY 2.0: A General-Purpose Parallel Molecular Dynamics Simulation Package. J. Mol. Graphics 1996, 14, 136-141.

(52) Smith, W.; Yong, C. W.; Rodger, P. M. DL_POLY: Application to Molecular Simulation. Mol. Simul. 2002, 28, 385-471.

(53) Todorov, I. T.; Smith, W.; Trachenko, K.; Dove, M. T. DL_POLY_3: New Dimensions in Molecular Dynamics Simulations via Massive Parallelism. J. Mater. Chem. 2006, 16, 1911-1918.

(54) Laio, A.; Gervasio, F. L. Metadynamics: A Method to Simulate Rare Events and Reconstruct the Free Energy in Biophysics, Chemistry and Material Science. Rep. Prog. Phys. 2008, 71, 126601.

(55) Grimme, S.; Antony, J.; Ehrlich, S.; Krieg, H. A Consistent and Accurate Ab Initio Parametrization of Density Functional Dispersion Correction (DFT-D) for the 94 Elements H-Pu. J. Chem. Phys. 2010, $132,154104$.

(56) Cnudde, P.; De Wispelaere, K.; Van der Mynsbrugge, J.; Waroquier, M.; Van Speybroeck, V. Effect of Temperature and Branching on the Nature and Stability of Alkene Cracking Intermediates in H-ZSM-5. J. Catal. 2017, 345, 53-69.

(57) Torrie, G. M.; Valleau, J. P. Nonphysical Sampling Distributions in Monte Carlo Free-Energy Estimation: Umbrella Sampling. J. Comput. Phys. 1977, 23, 187-199.

(58) Schüring, A.; Auerbach, S. M.; Fritzsche, S.; Haberlandt, R. On Entropic Barriers for Diffusion in Zeolites: A Molecular Dynamics Study. J. Chem. Phys. 2002, 116, 10890-10894.

(59) Vanduyfhuys, L.; Ghysels, A.; Rogge, S.M.J.; Demuynck, R.; Van Speybroeck, V. Semi-Analytical Mean-Field Model for Predicting Breathing in Metal-Organic Frameworks. Mol. Simul. 2015, 41, 13111328.

(60) Van Speybroeck, V.; Hemelsoet, K.; Joos, L.; Waroquier, M.; Bell, R. G.; Catlow, C. R. A. Advances in Theory and Their Application within the Field of Zeolite Chemistry. Chem. Soc. Rev. 2015, 44, 7044-7111.

(61) Cnudde, P.; De Wispelaere, K.; Vanduyfhuys, L.; Demuynck, R.; Van der Mynsbrugge, J.; Waroquier, M.; Van Speybroeck, V. How Chain Length and Branching Influence the Alkene Cracking Reactivity on H-ZSM-5. ACS Catal. 2018, 8, 9579-9595.

(62) Ramirez, A.; Dutta Chowdhury, A.; Dokania, A.; Cnudde, P.; Caglayan, M.; Yarulina, I.; Abou-Hamad, E.; Gevers, L.; Ould-Chikh, S.; De Wispelaere, K.; Van Speybroeck, V.; Gascon, J. Effect of Zeolite Topology and Reactor Configuration on the Direct Conversion of $\mathrm{CO}_{2}$ to Light Olefins and Aromatics. ACS Catal. 2019, 9, 6320-6334.

(63) Göltl, F.; Grüneis, A.; Bučko, T.; Hafner, J. Van Der Waals Interactions between Hydrocarbon Molecules and Zeolites: Periodic Calculations at Different Levels of Theory, from Density Functional Theory to the Random Phase Approximation and Møller-Plesset Perturbation Theory. J. Chem. Phys. 2012, 137, 114111.

(64) Gallego, E. M.; Chengeng, L.; Paris, C.; Martin, N.; MartinezTriguero, J.; Boronat, M.; Moliner, M.; Corma, A. Making Nanosized CHA Zeolites with Controlled Al Distribution for Optimizing Methanol-to-Olefin Performance. Chem. - Eur. J. 2018, 24, 1463114635 . 